\title{
Biomarkers and functional foods for obesity and diabetes
}

\author{
James O. Hill ${ }^{1}$ and John C. Peters ${ }^{2}$ \\ ${ }^{1}$ Center for Human Nutrition, University of Colorado, Health Sciences Center, Box C225, 4200 East Ninth Avenue, \\ Denver, CO 80262, USA \\ ${ }^{2}$ Procter \& Gamble Company, 6071 Center Hill Road, Cincinnati, OH 45224, USA
}

\begin{abstract}
Obesity has reached epidemic proportions in many countries around the world. Because of the close relationship between obesity and type 2 diabetes, an epidemic of diabetes is close behind the obesity epidemic. Preventing and treating obesity is becoming an increasing priority. In the United States, over $60 \%$ of the adult population is overweight or obese and thus at increased risk of developing diabetes and cardiovascular disease. While the aetiology of obesity and diabetes is complex, diet clearly plays an important role both in the development and management of these diseases. There is interest in functional foods that could help in prevention and/or management of obesity and type 2 diabetes. This could involve food products that help management of 'hunger' or that increase 'satiety'. It could also involve foods that contribute to more inefficient use of ingested energy (i.e. foods that stimulate energy expenditure more than would be expected from their energy content). As the concept of insulin sensitivity becomes generally more accepted by health care professionals and the public, foods may be targeted towards maximizing insulin sensitivity and towards 'prevention' of diabetes. In addition to foods that impact upon body weight, these may include foods that affect the glucose and/or insulin levels that are seen either following the ingestion of food or later in the day. The present paper reviews the complex aetiology of obesity and diabetes and considers a potential role for functional foods in prevention and treatment of obesity and diabetes.
\end{abstract}

Obesity: Type 2 diabetes: Biomarkers: Functional foods

\section{The need for tools to manage obesity}

The rate of increase in obesity in the US population has led many to label this public health threat as an epidemic. This is supported by data from the National Health and Nutrition Examination Surveys (National Center for Health Statistics, 1999) and by data from the Behavioral Risk Factor Surveillance System (Mokdad et al. 2001). All indications are that the prevalence of obesity will continue to increase over the next several years.

The obesity epidemic presents a serious threat to public health given the known relationship between obesity and other serious chronic diseases such as type 2 diabetes and cardiovascular disease (Pi-Sunyer, 1993; National Institutes of Health, 1998; Fagot-Campagna et al. 2000). In fact, there is convincing evidence that the obesity epidemic is being followed by an epidemic of type 2 diabetes (Harris et al. 1998). The metabolic syndrome (syndrome $\mathrm{X}$ or insulin-resistance syndrome) has been defined as a cluster of conditions including obesity (particularly visceral obesity) and insulin resistance that are frequently seen together and which impart increased risk of development of type 2 diabetes (Reaven, 1998). Thus, the vast majority of persons with type 2 diabetes are obese and weight loss may be one of the best treatments both to prevent and treat type 2 diabetes (Maggio \& Pi-Sunyer, 1997).

In general, efforts to treat obesity have not met with great success, but we may be more successful than popular belief. Obesity treatment guidelines issued by the National Institutes of Health (1998) suggest an initial goal of $10 \%$ weight loss for obesity treatment. Wing \& Hill (2001) have estimated that about $20 \%$ of those obese individuals who attempt weight loss are successful in achieving a $10 \%$ weight loss and maintaining that weight loss for a year. With over $60 \%$ of the US adult population being overweight or obese, there is great demand for better tools to help people achieve weight loss and maintenance of weight loss.

Treatment strategies for type 2 diabetes usually involve pharmacological treatment aimed at stimulating insulin secretion or increasing insulin sensitivity. The disease is progressive (leading to serious negative consequences such as blindness and kidney disease) and treatment aims to slow this progression (Lebovitz, 1994). Interestingly, 
many of the treatments for type 2 diabetes such as insulin and sulfonylureas have been shown to produce weight gain and potentially exacerbate the disease (UK Prospective Diabetes Study Group, 1998a,b).

Prevention of type 2 diabetes has recently been shown to be a promising strategy. The Finnish Diabetes Prevention Study (Tuomilehto et al. 2001) and the larger Diabetes Prevention Program (DPP Research Group, unpublished results) both found that the risk of developing diabetes in obese, insulin-resistant subjects could be cut by more than half by life-style modification. The life-style modification consisted of modest weight loss (about 5\%) and an increase in physical activity (thirty minutes of physical activity about three times per week).

\section{Modifying energy balance: biomarkers for obesity}

Obesity arises from an energy imbalance whereby energy intake exceeds energy expenditure. Dealing with obesity - either prevention or treatment - requires modification of one or both components of energy balance. Approaches to weight management (including a functional food approach) therefore can target multiple aspects of the energy balance systems: food intake, energy expenditure and energy storage. All of these approaches are currently being taken by pharmaceutical companies; however, developing foods for weight management may be a more attractive approach for dealing with the $61 \%$ of the population that is overweight or obese.

Regardless of the approach to weight management, a major limitation in assessing and documenting success is the lack of suitable biomarkers to assess the impact of different treatments on components of energy balance.

\section{Assessment of body energy stores}

Body weight can easily be assessed using a bathroom scale, but assessing the increased health risk of obesity is more difficult. The majority of data available relates BMI to morbidity and mortality (National Institutes of Health, 1998). While BMI (weight divided by the square of height) is obtained relatively easily, it does not provide information about body composition (i.e. body fat $v$. fat-free mass). Body composition can be assessed accurately in the laboratory, but these techniques are not readily available to the general population (Lohman, 2001). The techniques available to the general population for assessing body composition (such as bioelectrical impedance and skinfold thickness) are not considered to be highly accurate or precise (Lohman, 2001).

\section{Energy intake}

Total energy intake. It is surprisingly difficult to measure accurately the amount of energy consumed by a free-living individual. There are accurate tables for converting food eaten into energy ( $\mathrm{kJ}$ or $\mathrm{kg}$ ) consumed, but the difficulty is in determining the amount and composition of food eaten. The typical way of assessing food intake is to have individuals keep records of food eaten. This is frequently done using food diaries (for periods of three to seven days), 24-hour recalls of all food eaten during the previous twenty-four hours, or assessments of the frequency with which various foods are usually consumed (Westerterp, 1998). While these techniques allow estimation of energy intake, they lack both accuracy and precision (Heitman \& Lissner, 1995; Westerterp, 1998). For example, when comparing self-reported energy intake with accurate measures of energy expenditure (e.g. using doubly labelled water) for individuals in energy balance, estimated energy intake is usually below measured energy expenditure (Schoeller, 1995). Proponents of the use of dietary self-reports argue that even if the absolute energy intake is not accurate, the instruments provide an accurate reflection of changes in energy intake (Willett, 1990; Kristal et al. 1994). Whether this is the case or not is unclear.

Type of food eaten. There is great controversy about the role of diet composition in the development and management of obesity. It is likely that some functional foods aimed at reducing obesity will attempt to alter diet composition. Determining diet composition accurately may be even more difficult than determining total energy intake. Perhaps changes in protein intake are more easily assessed than changes in the other macronutrients. Protein intake is correlated with urinary and blood levels of nitrogen, and these can provide a biomarker of changes in dietary protein intake.

There is no universally accepted marker for carbohydrate intake. One can obtain some sense of type of carbohydrate intake from the glycaemic index, which is the rise in blood glucose after carbohydrate intake. Amount of carbohydrate intake is also correlated with insulin level, but it is not clear that either glucose or insulin level is a useful marker of changes in carbohydrate intake. Additionally these measurements are not easily available to the general population.

There is no clear useable biomarker for fat intake. The type of fat consumed chronically can be determined from biopsies of adipose tissue or from red blood cell membrane fatty acid composition (Wardlaw et al. 1994), but these techniques are invasive and do not provide information about the amount of fat consumed. Blood levels of cholecystokinin and enterostatin change with dietary intake but it is not clear that these blood changes allow accurate quantification of changes in dietary fat.

\section{Assessment of energy expenditure}

Functional foods that modify energy expenditure could be useful in weight management. Assessment of energy expenditure can be accomplished accurately under laboratory conditions using indirect calorimetry or doubly labelled water (Melby et al. 1998). There are currently no biomarkers for energy expenditure that are available to the general public. A new device called the Body GEM $^{\mathrm{TM}}$ has just gone on the market in the USA (Nieman et al. 2001) and appears to provide a measure of resting energy expenditure of individuals. Like more expensive hospital equipment, the Body GEM $^{\mathrm{TM}}$ determines energy expenditure from measurement of the amount of oxygen consumed by the body. Such measurements can be made 
relatively inexpensively in health clubs and by personal dietitians and personal trainers. Devices like this may be useful in assessing the efficacy of products to increase energy expenditure.

\section{Functional foods to reduce energy intake}

One promising avenue to reduce energy intake using functional foods is through increased satiety. The goal is to provide foods that increase the sense of fullness and encourage the individual to stop eating sooner, thereby reducing total energy intake. In general, the three most promising areas to increase satiety are to: (1) modify the energy density of the diet; (2) modify the macronutrient composition of the diet; and (3) modify the glycaemic index of the diet.

\section{Energy density}

The energy density of the diet is the energy content per unit of weight or volume and seems to be correlated with total energy intake (Rolls \& Bell, 1999, 2000; Stubbs et al. $1995 a, b)$. Energy density is relatively easy to measure for most foods and can be calculated by dividing the energy content of the food in $\mathrm{kJ}$ by the weight or volume of the food (Rolls \& Barnett, 2000). In their book Volumetrics, Rolls \& Barnett (2000) explain the concept of energy density and provide energy density values for a range of foods.

There are substantial data to suggest that total energy intake over the short term (a few days) varies directly with the energy density of the diet (Rolls \& Bell, 1999, 2000; Stubbs et al. 1995a,b). One physiological signal for satiety may relate to the total weight or volume of food ingested. This suggests that modifying the energy density of the diet could be a way to reduce total energy intake and reduce obesity. The main determinant of energy density is the non-caloric content of the food, primarily the water content (Grunwald et al., 2001). Foods with a high water content have a low energy density. Fibre also reduces energy density since it contributes substantially more to food weight than to caloric content. However, energy density is also affected by the macronutrient composition of the diet. Since fat is more energy-dense $(38 \mathrm{~kJ} / \mathrm{g})$ than either protein or carbohydrate $(17 \mathrm{~kJ} / \mathrm{g})$, reducing the proportion of fat in the diet can have a major impact on reducing the energy density of the diet. Since there are solid data showing that reducing energy density reduces energy intake (at least in the short term), functional foods aimed at modifying energy density may be useful in managing obesity. It would be helpful to have more long-term data substantiating the effect of energy density and relating energy density to changes in body weight.

\section{Macronutrient composition and satiety}

Researchers often refer to a hierarchy of satiety for macronutrients with protein being the most satiating and fat the least satiating, joule for joule (Hill \& Prentice, 1995). High-protein diets are currently popular for weight loss and are based, in part, on the idea that high-protein diets promote satiety. Popular diet books such as New Diet Revolution (Atkins, 1992) and Protein Power (Eades \& Eades, 1996) are based on this premise. The data in support of high-protein diets as facilitators of weight loss and weight maintenance are still incomplete. Some studies suggest that high-protein diets may be effective in producing short-term decreases in food intake (Rolls et al. 1988) but whether or not these diets are helpful in long-term weight maintenance or in prevention of weight gain is not clear.

With regard to satiety and carbohydrate intake, it may depend on the type of carbohydrate in the diet. While intake of simple carbohydrate or sugar has been suggested by the popular press to be associated with the development of obesity, it is not clear that high-sugar diets lead to overeating or obesity compared with low-sugar diets (Lewis et al. 1992; Hill \& Prentice, 1995; Ludwig et al. 2001).

It has also been suggested that calories in liquid form may affect satiety less strongly than solid foods with the same calorie content (Mattes, 1996). While the available data are not definitive, if substantiated they could implicate caloric beverages as a facilitator of overeating and a causal factor in obesity. Most calories in beverages are in the form of carbohydrates, and there is little information about whether different types of carbohydrates in liquid form might affect energy intake differently.

Dietary fibre intake seems to best predict total energy intake, with several reports of lower total energy intake with high-fibre $v$. low-fibre diets (Pereira \& Ludwig, 2001). There are probably several reasons why high-fibre diets are associated with lower food intake. First, highfibre diets may trigger maximal sensory stimulation in the mouth due to the increased need for chewing. Highfibre diets also lead to slower gastric emptying and a slower rate of nutrient absorption. Finally, a high fibre content reduces the energy density of the overall diet. Regardless of the reason, increasing dietary fibre is generally thought to aid in weight management. Ludwig et al. (1999) found that high dietary fibre seemed protective against weight gain over a decade.

Modification of dietary fat type is not a commonly accepted strategy for weight loss. There is some suggestion that diets high in polyunsaturated fatty acids stimulate total fat oxidation more than diets high in saturated fatty acids (Jones \& Schoeller, 1988) but this is somewhat controversial. Other fats such as short- and medium-chain triacylglycerols and $n-3$ fatty acids may have a greater impact on energy metabolism but it is not clear that these would play a major role in weight management.

\section{Glycaemic index and satiety}

The glycaemic index of a food is determined by the rise in glucose that occurs after eating that food in relation to the rise in glucose seen after eating a standardized food such as white bread (Brand-Miller et al. 1999). This obviously requires measuring glucose after consuming a food. High glucose levels following eating would stimulate insulin secretion which may increase appetite and facilitate other disease processes linked to insulin action. In their book, 
The Glucose Revolution, Brand-Miller et al. (1999) provide the rationale for how glycaemic index may affect food intake and obesity, and provide tables of glycaemic index for many foods.

Whether or not the glycaemic index of the diet affects energy intake and obesity remains controversial. There is no convincing evidence that food intake is related directly to glycaemic index, although there is some evidence that high glycaemic diets are linked to weight gain (Ludwig, 2000). The glycaemic index of the total diet could be modified by eating foods with a low glycaemic index. If the glycaemic index were shown to affect food intake, a good target would be to develop more good-tasting, low glycaemic foods.

\section{Functional foods to increase energy expenditure}

Another way to reduce the likelihood of developing obesity or to treat obesity would be to increase total energy expenditure without increasing energy intake. While some food supplements make the claim of increasing energy expenditure, there are very few data available to support the efficacy of these products.

One product on the market that has some demonstrated efficacy is the combination of caffeine and ephedrine. This combination has been shown to increase energy expenditure modestly and is used for obesity treatment in some countries (Astrup et al. 1992). There has been recent concern about the long-term safety of ephedrine.

Recently it has been suggested that diets high in Ca may be protective against weight gain and that part of the mechanism may be an increase in energy expenditure (Zemel et al. 2000). In several datasets, high $\mathrm{Ca}$ intake is associated with a lower BMI (Davies et al. 2000), but there has yet been no clear demonstration that this is a causal relationship.

Oolong tea is another food that may have some impact on increasing energy expenditure (Rumpler et al. 2001), perhaps through its catechin content. Resting metabolic rate was increased by 3-4\% during three days of oolong tea consumption at five cups per day. Interestingly, most of the rise in metabolic rate was from increased fat oxidation, which should have the greatest impact upon decreasing body fat stores.

\section{Functional foods to alter nutrient partitioning}

If some of the energy ingested is not absorbed completely, this can reduce net energy available to meet metabolic demands and can lead to weight loss. The approaches that have been taken involve blocking absorption of carbohydrates (starch blockers) or fats (fat blockers). The impact of the currently available products (e.g. Acarbose) is not clear.

\section{Non-absorbable fats}

Olestra is a non-absorbable fat substitute that has been shown to reduce total energy intake (Hill et al. 1998), and to be effective in producing weight loss (Bray et al. 2002). Olestra was approved by the Food and Drug
Administration in 1996 for use in savoury snack products. Post market surveillance data suggest an association between Olestra intake and weight maintenance. The mechanism for a positive obesity effect may be its effects on reducing energy density, although other mechanisms cannot be ruled out.

\section{Functional foods to prevent or manage diabetes}

The results of the Finnish Diabetes Prevention Study (Tuomilehto et al. 2001) and the larger Diabetes Prevention Program (DPP Research Group, unpublished results) show that modest weight loss (about $5 \%$ ) can reduce the development of type 2 diabetes by half in individuals at risk for this disease. There is a tremendous opportunity to develop functional foods targeted at those at risk for type 2 diabetes (i.e. insulin-resistant) to help them achieve modest weight reduction. Theoretically, any functional food that helped with weight loss could be marketed as helping prevent diabetes in an insulin-resistant population. Furthermore, it may be possible to target functional foods towards management of diabetes in those who already have type 2 diabetes. It is clear that weight control is an effective diabetes management technique and, here again, functional food aimed at weight loss could be targeted towards those with type 2 diabetes. Moreover, it may be possible to develop functional foods that impact insulin action independently of weight loss. These would probably be foods that increase the sensitivity of peripheral tissues to insulin, or insulin sensitizers.

\section{Insulin sensitizers}

There are currently food supplements that claim to increase insulin sensitivity, but there is very little evidence about the effectiveness of these products. Perhaps the most widely available of these is chromium picolinate, which under some circumstances appears to affect insulin action (Cefalu et al. 1999). Such products have not yet been proved to be effective in treating diabetes.

\section{The future: possibilities for new biomarkers}

While we see a clear opportunity to develop and market more functional foods for weight management, the lack of accurate biomarkers to assess their effectiveness is a barrier to this process. The future may hold promise for developing better biomarkers and this would greatly facilitate the development of functional foods.

It is almost certain that better and more accessible methods of measuring body composition will be available in the future. Accurate body composition, including body fat distribution, is not available on a widespread basis outside laboratory settings. This is likely to change with additional technological advances.

It is likely that we will develop better ways of assessing total energy intake and intake of specific macronutrients by adding non-metabolizable substances to the diet and monitoring their excretion. This will allow better assessment of the effectiveness of functional food for changing total energy intake or macronutrient content of the diet. 
As recognition of the need to assess and treat the metabolic syndrome grows, physicians and other health care professionals will be screening patients for insulin resistance. It is likely that there will soon be consensus on how to do this, thus providing a standardized way of assessing insulin resistance that can be used to assess any change in response to functional foods.

\section{References}

Astrup A, Buemann B, Christensen NJ, Toubro S, Thorbek G, Victor OJ \& Quaade F (1992) The effect of ephedrine/caffeine mixture on energy expenditure and body composition in obese women. Metabolism 41, 686-688.

Atkins RC (1992) Dr. Atkins' New Diet Revolution. New York: Avon Books.

Brand-Miller J, Wolever TMS, Colagiuri S \& Foster-Powell K (1999) The Glucose Revolution. New York: Marlowe \& Company.

Bray GA, Lovejoy JC, Most-Windhauser M, Smith SR, Volaufova J, Denkins Y, DeJonge L, Rood J, Lefevre M, Eldridge AL \& Peters JC (2002) A nine-month randomized clinical trial comparing a fat-substituted and fat-reduced diet in healthy obese men: The Ole Study. American Journal of Clinical Nutrition in press.

Cefalu WT, Bell-Farrow AD, Stegner J, Shong QW, King T, Morgan T \& Terry JG (1999) Effect of chromium picolinate on insulin sensitivity in vivo. Journal of Trace Elements in Experimental Medicine 12, 71-83.

Davies KM, Heaney RP, Recker RR, Lappe JM, Barger-Lux J, Rafferty K \& Hinders S (2000) Calcium intake and body weight. Journal of Clinical Endocrinology and Metabolism 85, 4635-4638.

Eades MR \& Eades MD (1996) Protein Power. New York: Bantam Books.

Fagot-Campagna A, Pettitt DJ, Englegau MM, Burrows NR, Geiss LS, Valdez R, Beckles GL, Saadine J, Gregg EW, Williamson DF \& Jarayan KMV (2000) Type 2 diabetes among North American children and adolescents: an epidemiologic review and a public health perspective. Journal of Pediatrics 136, 664-672.

Grunwald GK, Seagle HM, Peters JC \& Hill JO (2001) Quantifying and separating the effects of macronutrient composition and non-energetic food components on energy density. British Journal of Nutrition 86, 265-276.

Harris MI, Flegal KM, Cowie CC, Eberhardt MS, Goldstein DE, Little RR, Wiedmeyer HM \& Byrd-Holt DD (1998) Prevalence of diabetes, impaired fasting glucose, and impaired glucose tolerance in US adults. The Third National Health and Nutrition Examination Survey, 1988-1994. Diabetes Care 21, 518-524.

Heitman BL \& Lissner L (1995) Dietary underreporting by obese individuals - is it specific or non-specific? British Medical Journal 311, 986-989.

Hill JO \& Prentice AM (1995) Sugar and body weight regulation. American Journal of Clinical Nutrition 62, 264S-274S.

Hill JO, Seagle HM, Johnson SL, Smith S, Reed GW, Tran ZV, Cooper D, Stone M \& Peters JC (1998) Effects of 14 days of covert substitution of Olestra on spontaneous food intake. American Journal of Clinical Nutrition 67, 1178-1185.

Jones PJH \& Schoeller DA (1988) Polyunsaturated:saturated ratio of diet fat influences energy substrate utilization in the human. Metabolism 37, 145-151.

Kristal AR, Beresford SA \& Lazovich D (1994) Assessing change in diet-intervention research. American Journal of Clinical Nutrition 59, 185S-189S.

Lebovitz HE (1994) Stepwise and combination drug therapy for the treatment of NIDDM. Diabetes Care 17, 1542-1544.

Lewis CJ, Park YK, Dexter PB \& Yetley EA (1992) Nutrient intakes and body weight of persons consuming high and moderate levels of sugars. Journal of the American Dietetic Association 92, 703-713.

Lohman TG (2001) Body composition. In Eating Disorders and Obesity: A Comprehensive Handbook, 2nd ed., pp. 62-66 [C Fairburn and K Brownell, editors]. New York: Guilford.

Ludwig DS (2000) Dietary glycemic index and body weight regulation. Nutrition Society of Australia 24, 286-293.

Ludwig DS, Pereira MA, Kroenke CH, Hilner JE, Van Horn L, Slattery ML \& Jacobs DR Jr (1999) Dietary fiber, weight gain and cardiovascular disease risk factors in young adults: the CARDIA study. Journal of the American Medical Association 282, 1539-1546.

Ludwig DS, Peterson KE \& Gortmaker SL (2001) Relation between consumption of sugar-sweetened drinks and childhood obesity: a prospective, observational analysis. Lancet 357, 505-508.

Maggio CA \& Pi-Sunyer FX (1997) The prevention and treatment of obesity. Application to type 2 diabetes. Diabetes Care 20, $1744-1766$.

Mattes RD (1996) Dietary compensation by humans for supplemental energy provided as ethanol or carbohydrate in fluids. Physiology and Behavior 59, 179-187.

Melby CR, Ho R \& Hill JO (1998) Assessment of energy expenditure. In Physical Activity and Obesity, pp. 204-233 [C Bouchard, editor]. Champaign, IL: Human Kinetics.

Mokdad H, Bowman BA, Ford ES, Vinicor F, Marks JS \& Koplan JP (2001) The continuing epidemics of obesity and diabetes in the United States. Journal of the American Medical Association 286, 1195-1200.

National Center for Health Statistics (1999) Prevalence of overweight and obesity among adults: United States (electronic citation). http://www.cdc.gov/nchs/products/pubs/pubd/hestats/ obese/obsc99.htm.

National Institutes of Health (1998) Clinical guidelines on the identification, evaluation, and treatment of overweight and obesity in adults - the Evidence Report. Obesity Research 6, Suppl. 2, 51S-210S.

Nieman DC, Trone G \& Austin M (2001) Validation of a new handheld device for measuring resting metabolic rate. Obesity Research 9, Suppl. 3, 202S.

Pereira MA \& Ludwig DS (2001) Dietary fiber and body weight regulation: observations and mechanisms. Pediatrics Clinics of North America 48, 969-980.

Pi-Sunyer FX (1993) Medical hazards of obesity. Annals of Internal Medicine 119, 655-660.

Reaven GM (1998) Role of insulin resistance in human disease. Diabetes 37, 1595-1607.

Rolls B \& Barnett RA (2000) Volumetrics. New York: HarperCollins.

Rolls BJ \& Bell EA (1999) Intake of fat and carbohydrate: role of energy density. European Journal of Clinical Nutrition $\mathbf{5 2}$ $1-8$.

Rolls BJ \& Bell EA (2000) Dietary approaches to the treatment of obesity. Medical Clinicians of North America 84, 401-418.

Rolls BJ, Hetherington M \& Burley VJ (1988) The specificity of satiety: the influence of foods of different macronutrient content on the development of satiety. Physiology and Behavior 43, $145-153$.

Rumpler W, Seale J, Clevidence B, Judd J, Wiley E, Yamamoto S, Komatsu T, Sawaki T, Ishikura Y \& Hosoda K (2001) 
Oolong tea increases metabolic rate and fat oxidation in men. Journal of Nutrition 131, 2848-2852.

Schoeller DA (1995) Limitations in the assessment of dietary energy intake by self-report. Metabolism 44, Suppl. 2, 18-22. Stubbs RJ, Harbron CG, Murgatroyd PR \& Prentice AM (1995a) Covert manipulation of dietary fat and energy density: effect on substrate flux and food intake in men eating ad libitum. American Journal of Clinical Nutrition 62, 316-329.

Stubbs RJ, Ritz P, Coward WA \& Prentice AM (1995b) Covert manipulation of the ratio of dietary fat to carbohydrate and energy density: effect on food intake and energy balance in free-living men eating ad libitum. American Journal of Clinical Nutrition 62, 330-337.

Tuomilehto J, Lindstrom J, Eriksson JG, Valle TT, Hamalainen H, Ilanne-Parikka P, Seinanen-Kiukaanniemi SK, Laakso M, Louheranta A, Rastas M, Salminen V \& Uusitupa M (2001) Prevention of type 2 diabetes mellitus by changes in lifestyle among subjects with impaired glucose tolerance. New England Journal of Medicine 344, 1343-1350.

UK Prospective Diabetes Study Group (1998a) United Kingdom Prospective Diabetes Study 24: a 6-year, randomized, controlled trial comparing sulfonylurea, insulin, and metformin therapy in patients with newly diagnosed type 2 diabetes that could not be controlled with diet therapy. Annals of Internal Medicine 128, 165-175.

UK Prospective Diabetes Study Group (1998b) Intensive blood-glucose control with sulphonylureas or insulin compared with conventional treatment and risk of complications in patients with type 2 diabetes (UKPDS 33). Lancet 352, 837-853.

Wardlaw GM, Snook JT, Park S, Patel PK, Pendley FC, Lee M \& Jandacek RJ (1994) Relative effects on serum lipids and apolipoproteins of a caprenin-rich diet compared with diets rich in palm oil/palm-kernel oil or butter. American Journal of Clinical Nutrition 61, 535-542.

Westerterp KR (1998) The assessment of energy and nutrient intake in humans. In Physical Activity and Obesity, pp. 133-149 [C Bouchard, editor]. Champaign, IL: Human Kinetics.

Willett W (1990) Nutritional Epidemiology. New York: Oxford University Press.

Wing RR \& Hill JO (2001) Successful weight loss maintenance. Annual Reviews of Nutrition 21, 323-341.

Zemel MB, Shi H, Greer B, Dirienzo D \& Zemel PC (2000) Regulation of adiposity by calcium. FASEB Journal 14, $1132-1138$ 